\title{
Blocking CD248 molecules in perivascular stromal cells of patients with systemic sclerosis strongly inhibits their differentiation toward myofibroblasts and proliferation: a new potential target for antifibrotic therapy
}

Paola Di Benedetto ${ }^{1 *} \mathbb{D}$, Vasiliki Liakouli ${ }^{1}$, Piero Ruscitti ${ }^{1}$, Onorina Berardicurti ${ }^{1}$, Francesco Carubbi ${ }^{1}$, Noemi Panzera', Salvatore Di Bartolomeo', Giuliana Guggino², Francesco Ciccia², Giovanni Triolo², Paola Cipriani ${ }^{1}$ and Roberto Giacomelli ${ }^{1}$

\begin{abstract}
Background: Fibrosis may be considered the hallmark of systemic sclerosis (SSc), the end stage triggered by different pathological events. Transforming growth factor- $\beta$ (TGF- $\beta$ ) and platelet-derived growth factor BB (PDGF-BB) are profibrotic molecules modulating myofibroblast differentiation and proliferation, respectively. There is evidence linking CD248 with these two molecules, both highly expressed in patients with SSc, and suggesting that CD248 may be a therapeutic target for several diseases. The aim of this work was to evaluate the expression of CD248 in SSC skin and its ability to modulate SSc fibrotic process.

Methods: After ethical approval was obtained, skin biopsies were collected from 20 patients with SSC and 10 healthy control subjects (HC). CD248 expression was investigated in the skin, as well as in bone marrow mesenchymal stem cells (MSCs) treated with TGF- $\beta$ or PDGF-BB, by immunofluorescence, qRT-PCR, and Western blotting. Finally, in SSc-MSCs, the CD248 gene was silenced by siRNA.

Results: Increased expression of CD248 was found in endothelial cells and perivascular stromal cells of SSc skin. In SSc-MSCs, the levels of CD248 and a-smooth muscle actin expression were significantly higher than in HC-MSCs. In both SSC- and HC-MSCS, PDGF-BB induced increased expression of Ki-67 when compared with untreated cells but was unable to modulate CD248 levels. After CD248 silencing, both TGF- $\beta$ and PDGF-BB signaling were inhibited in SSC-MSCS.

Conclusions: CD248 overexpression may play an important role in the fibrotic process by modulating the molecular target, leading to perivascular cells differentiation toward myofibroblasts and interfering with its expression, and thus might open a new therapeutic strategy to inhibit myofibroblast generation during SSc.
\end{abstract}

Keywords: Systemic sclerosis, CD248, Fibrosis

\footnotetext{
* Correspondence: paola.dibenedetto1@univaq.it

${ }^{1}$ Department of Biotechnological and Applied Clinical Sciences,

Rheumatology Unit, School of Medicine, University of L'Aquila, Delta 6

Building, Via dell'Ospedale, 67100 L'Aquila, Italy

Full list of author information is available at the end of the article
}

(c) The Author(s). 2018 Open Access This article is distributed under the terms of the Creative Commons Attribution 4.0 International License (http://creativecommons.org/licenses/by/4.0/), which permits unrestricted use, distribution, and

reproduction in any medium, provided you give appropriate credit to the original author(s) and the source, provide a link to the Creative Commons license, and indicate if changes were made. The Creative Commons Public Domain Dedication waiver (http://creativecommons.org/publicdomain/zero/1.0/) applies to the data made available in this article, unless otherwise stated. 


\section{Background}

CD248 (also known as endosialin or tumor endothelial marker 1) is a transmembrane receptor whose known ligands are fibronectin and type I/IV collagen. It is widely expressed on mesenchymal cells during embryonic life and is required for proliferation and migration of pericytes and fibroblasts [1]. Although CD248 expression is dramatically reduced during adult life, it may be upregulated during specific conditions such as malignancy, inflammation, and fibrosis [2-4]. It is well known that CD248 is expressed on the surface of cells of mesenchymal origin, including tumor-associated pericytes and activated fibroblasts, which are thought to play a key role in the development of tumor neovascular networks and stromal interaction [1]. The interruption of endosialin function, with antibody blockade or genetic knockouts, negatively affects tumor growth and angiogenesis in numerous cancer types [5-7]. Furthermore, in the experimental model of kidney fibrosis after unilateral ureteral obstruction (UUO), CD248 ${ }^{-/-}$mice display downregulation of myofibroblast proliferation, thus decreasing the kidney fibrosis [8]. These biologic effects, in cancer and in reparative response, may be related to the ability of CD248 to modulate many signaling pathways involved in both cancer development and tissue repair, including platelet-derived growth factor BB (PDGF-BB), transforming growth factor- $\beta$ (TGF- $\beta$ ), and Notch receptor protein [9]. Under normal conditions, pericytes that expressed high levels of CD248 were able to proliferate, responding to PDGF-BB stimulation [9], and higher expression of CD248 is required for imparting fibroblast sensitivity to the effects of TGF- $\beta$ [10].

Owing to its multifunctional activities modulating innate immunity, cell proliferation, and vascular homeostasis [9, 11], CD248 may be considered a potential therapeutic target for several diseases [12], and currently, the results of a first-in-human, open-label, phase I study recruiting patients with extracranial solid tumors who failed standard chemotherapy and were treated with a biologic therapy targeting CD248 have been published, confirming the therapy's safety and a positive impact on different cancers [13].

Systemic sclerosis (SSc) is a connective tissue disease of unknown etiology with multiorgan involvement and heterogeneous clinical manifestations. The hallmark of early SSc is endothelial involvement, whereas later stages are characterized by an excessive accumulation of extracellular matrix (ECM), resulting in extended fibrosis in skin and internal organs $[14,15]$. In the last few years, it has been clarified that endothelial cells (ECs) and pericytes, after injury, may differentiate toward myofibroblasts, which are committed to producing increased amounts of collagen [16-18], and this process has been proposed as a key pathogenic mechanism in SSc.
Several polypeptide mediators are involved in fibrosis during SSc, such as TGF- $\beta$ and PDGF-BB. The latter is a potent pro-proliferative signal for mesenchyme-derived cells, including myofibroblasts $[19,20]$, whereas TGF- $\beta$ primarily promotes myofibroblast activation, $\alpha$-smooth muscle actin $(\alpha-S M A)$ expression, and collagen deposition [16, 21-26]. Interestingly, CD248 modulates both these pathways because of CD248 is required for imparting fibroblast sensitivity to the effects of TGF- $\beta$ [9] and is crucial for optimal migratory response of activated fibroblasts to PDGF-BB [19].

The goal of this work is to investigate the expression of CD248 in skin perivascular stromal cells from patients with SSc and its ability in mediating pericyte differentiation toward myofibroblasts. Although the role of CD248 in the pathogenesis of SSc has not yet been established, its potential role in controlling vessel regression and fibrosis makes this molecule a potential therapeutic target in a clinical setting, different from cancer, and in which an effective therapeutic approach to prevent fibrosis is still an important unmet need.

\section{Methods}

Patients, control subjects, and skin biopsies

Full-thickness biopsy samples measuring $2 \times 0.5 \mathrm{~cm}$ isolated from excisional biopsy were obtained from clinically involved skin of one-third of the distal forearm of patients with diffuse SSc according to the classification of LeRoy and colleagues [27]. All patients fulfilled the 2013 classification criteria for SSc [28]. Skin with a modified Rodnan skin score [29] $\geq 1$ was considered to be clinically involved.

To be sure that $50 \%$ of our patients were in a very early phase of SSc, considering that the term early currently refers to an undifferentiated connective tissue disease at higher risk of developing into scleroderma, as suggested by the pivotal study of Koening et al. [30], more than to a time frame from the beginning of the disease, we further divided our patients into two subsets: patients fulfilling the classification criteria in less than 1 year from the onset of Raynaud's phenomenon (early-onset subset [EOS], $n=10$ ) and all the others (long-standing subset [LSS], $n=10$ ). Skin samples from the same region of ten age- and sex-matched healthy control subjects $(\mathrm{HC})$ who underwent a surgical treatment for trauma were used for comparison. All patients with SSc underwent a 20-day washout from any immunosuppressive treatment and 1 month from intravenous prostanoids before skin biopsy was performed. During this period, only proton pump inhibitors and clebopride were allowed. Patients who could not undergo therapeutic washout owing to severe organ complications were not enrolled in the study. Biopsies were taken after informed consent was obtained, and the study was approved by 
our local ethics committee (ASL Avezzano Sulmona L'Aquila, protocol number 015408/17). Demographic and clinical characteristics of the patients are shown in Table 1. Each biopsy sample was divided into specimens for immunofluorescence (IF) and qRT-PCR. For IF, the specimens were fixed in $10 \%$ buffered formalin, dehydrated in graded alcohol series, and embedded in paraffin. Specimens used for qRT-PCR analyses were immediately immersed in liquid nitrogen and stored at $-80{ }^{\circ} \mathrm{C}$ until use.

\section{Immunofluorescence}

The IF analysis was performed on paraffin sections (thickness $3 \mu \mathrm{m}$ ) using a conjugated anti-CD248 antibody (Novus Biologicals, Littleton, CO, USA). Antigen retrieval was carried out using Dako Target Retrieval solution (Agilent Technologies, Santa Clara, CA, USA). Vasculature pericytes were highlighted using a Cy3-conjugated anti- $\alpha$-SMA antibody (Sigma-Aldrich, St. Louis, MO, USA) and EC using unconjugated anti-von Willebrand factor (vWF) antibody (Dako, Glostrup, Denmark). The immunoreaction was revealed using secondary antibody
(Alexa Fluor; Life Technologies, Carlsbad, CA, USA). Cell nuclei were visualized using 4',6-diamidino-2phenylindole. Fluorescence was analyzed using a BX53 fluorescence microscope (Olympus, Center Valley, PA, USA). The intensity of fluorescence was measured using ImageJ software (National Institutes of Health, Bethesda, MD, USA).

\section{Isolation, culture, and immunophenotyping of mesenchymal stem cells}

After approval was provided by the local ethics committee (ASL Avezzano Sulmona L'Aquila) and written informed consent was obtained from patients, bone marrow was obtained by aspiration from the posterior superior iliac crest from the patients enrolled in the study. Samples of mesenchymal stem cells (MSC) from bone marrow donors were used as a control. MSC were obtained and expanded from both the subsets of five EOS and five LSS patients, as previously described [25]. Third-passage MSC were analyzed for the surface expression of MSC antigens (CD45, CD73, CD90, CD34, CD79a, PDGF receptor- $\beta$ ) and pericyte markers ( $\alpha$-SMA, SM22 $\alpha$, NG2, desmin, RGS5) by flow

Table 1 Clinical and demographic features of the 20 patients with diffuse systemic sclerosis

\begin{tabular}{|c|c|c|c|c|c|c|c|c|}
\hline Sex/age (yr) & $\begin{array}{l}\text { Disease duration at skin } \\
\text { biopsy (yr from RP) }\end{array}$ & $\begin{array}{l}\mathrm{mRSS} / \mathrm{score} \text { at } \\
\text { skin biopsy }\end{array}$ & Autoantibodies & ILD & $\mathrm{PAH}$ & SRC & $\mathrm{RP}$ & DU \\
\hline $95 \% \mathrm{~F}$ & $\begin{array}{l}50 \% \text { EOS } \\
50 \% \text { LSS }\end{array}$ & & $100 \%$ ANA/Scl70 & $25 \%$ ILD & $15 \% \mathrm{PAH}$ & $0 \%$ SCR & $100 \% \mathrm{RP}$ & $30 \%$ DU \\
\hline$F / 45$ & $<1$ & $10 / 2$ & ANA/Scl-70 & No & No & No & Yes & No \\
\hline$F / 22$ & $<1$ & $13 / 1$ & ANA/Scl-70 & No & No & No & Yes & Yes \\
\hline$F / 31$ & $<1$ & $08 / 2$ & ANA/Scl-70 & No & No & No & Yes & No \\
\hline$F / 38$ & $<1$ & $09 / 2$ & ANA/Scl-70 & No & Yes & No & Yes & Yes \\
\hline$M / 20$ & $<1$ & $11 / 1$ & ANA/Scl-70 & No & No & No & Yes & No \\
\hline$F / 40$ & $<1$ & $10 / 2$ & ANA/SCl-70 & No & No & No & Yes & $\mathrm{No}$ \\
\hline$F / 31$ & $<1$ & $10 / 1$ & ANA/Scl-70 & No & No & No & Yes & No \\
\hline$F / 21$ & $<1$ & 09/1 & ANA/SCl-70 & No & No & No & Yes & $\mathrm{No}$ \\
\hline$F / 31$ & $<1$ & $14 / 1$ & ANA/SCl-70 & No & No & No & Yes & $\mathrm{No}$ \\
\hline$F / 42$ & $<1$ & $16 / 2$ & ANA/Scl-70 & Yes & No & No & Yes & $\mathrm{No}$ \\
\hline$F / 45$ & 4 & $17 / 2$ & ANA/Scl-70 & No & No & No & Yes & $\mathrm{No}$ \\
\hline$F / 21$ & 5 & $15 / 1$ & ANA/Scl-70 & No & No & No & Yes & No \\
\hline $\mathrm{F} / 30$ & 6 & $18 / 2$ & ANA/Scl-70 & No & Yes & No & Yes & Yes \\
\hline$F / 33$ & 4 & $13 / 2$ & ANA/Scl-70 & Yes & No & No & Yes & No \\
\hline$F / 34$ & 4 & $12 / 1$ & ANA/Scl-70 & No & No & No & Yes & Yes \\
\hline$F / 40$ & 4 & $10 / 2$ & ANA/SCl-70 & Yes & Yes & No & Yes & No \\
\hline$M / 26$ & 6 & $10 / 2$ & ANA/Scl-70 & Yes & No & No & Yes & Yes \\
\hline$F / 21$ & 4 & $11 / 1$ & ANA/Scl-70 & No & No & No & Yes & $\mathrm{No}$ \\
\hline$F / 30$ & 3 & $12 / 2$ & ANA/Scl-70 & Yes & No & No & Yes & Yes \\
\hline$F / 33$ & 4 & $12 / 1$ & ANA/Scl-70 & No & No & No & Yes & No \\
\hline
\end{tabular}

Abbreviations: EOS Early-onset subset, LSS Long-standing subset, RP Raynaud's phenomenon, mRSS Modified Rodnan skin score (maximum possible score 51), ILD Interstitial lung disease, ANA Antinuclear antibodies, SCl-70 Antitopoisomerase, PAH Pulmonary arterial hypertension, SRC Scleroderma renal crisis, DU Digital ulcers The internal organ involvement is referred to the time of biopsies 
cytometry (FACScan; BD Biosciences, San Jose, CA, USA) as previously described [25] (data not shown).

\section{MSC response to PDGF-BB and TGF- $\beta$}

To establish the optimal concentration of PDGF-BB and TGF- $\beta$ molecules, in our system, a dose-response curve was created, using P3 cells of one $\mathrm{HC}$ and one patient and evaluating the $\mathrm{Ki}-67$ and $\alpha$-SMA messenger RNA (mRNA) expression. Each experiment was performed in triplicate (data not shown). Both SSc-MSC and HCMSC were cultured for 7 days in 1\% FBS medium supplemented with selected doses of $10 \mathrm{ng} / \mathrm{ml}$ PDGF-BB (R\&D Systems, Minneapolis, MN, USA) and $10 \mathrm{ng} / \mathrm{ml}$ TGF- $\beta$ (R\&D Systems). We used the TGF- $\beta 1$ isoform. Media were changed every 2 days.

\section{Small interfering RNA assay}

To silence CD248 expression, SSc-MSC were transfected with Silencer Select CD248 small interfering RNA (siRNA; Life Technologies) [31] or with Silencer Select nontargeting scrambled (scr) siRNA (Life Technologies) using Lipofectamine 2000 reagent (Life Technologies). The CD248 gene was identified to be transcribed from a 2557-bp single-exon gene [32, 33].

Transfection was performed according to the manufacturer's instructions. Briefly, MSC were plated at $1 \times$ $10^{4}$ cells $/ \mathrm{cm}^{2} 24 \mathrm{~h}$ prior to transfection. Cultures were incubated for $24 \mathrm{~h}$ with $30 \mathrm{pmol}$ of siRNA in $2 \mathrm{ml}$ of Opti-MEM (Life Technologies). After incubation, plates were washed, and cells were allowed to recover in growth conditions (1\% FBS) supplemented with TGF- $\beta$ $(10 \mathrm{ng} / \mathrm{ml})$ and PDGF-BB $(10 \mathrm{ng} / \mathrm{ml})$.

\section{Western blot analysis}

MSC, derived from two EOS and two LSS patients, were pelleted and lysed in lysis buffer (radioimmunoprecipitation assay buffer; Cell Signaling Technology, Danvers, MA, USA) for $30 \mathrm{~min}$ and cleared by centrifugation. The protein concentration was calculated by using a bicinchoninic acid protein assay kit (EuroClone, Pero, Italy). Proteins $(40 \mu \mathrm{g})$ were separated by SDS-PAGE and transferred to nitrocellulose membranes. After blocking in 10\% nonfat milk in Tris-buffered saline/1\% Tween 20 and incubated with the primary antibodies $\alpha$-SMA (Santa Cruz Biotechnology, Dallas, TX, USA) and CD248 (Novus Biologicals), horseradish peroxidase-conjugated secondary antibodies (Cell Signaling Technology) were appropriately used. The detection was performed using long-lasting chemiluminescent substrate (EuroClone). All the signals were quantified by normalizing to the $\beta$-actin signal (Santa Cruz Biotechnology). Immunoreactive bands were acquired using a ChemiDoc imaging system with Image Lab software (Bio-Rad Laboratories, Hercules, CA, USA) and quantified with densitometry using ImageJ software.

\section{qRT-PCR analysis}

Total RNA was extracted from MSC and whole biopsy using NucleoSpin RNA (Macherey-Nagel, Düren, Germany) and reverse-transcribed into complementary DNA (cDNA) with the High Capacity cDNA Reverse Transcription Kit (Applied Biosystems, Foster City, CA, USA). The qRT-PCR was run in triplicate. Ki-67 and GAPDH gene expression were assessed using commercial TaqMan gene expression assay (Hs01032443_m1; Hs02 758991_g1, respectively). $\alpha$-SMA, CD248, and $\beta$-actin expression was performed by using SYBR Green kits (Applied Biosystems). Primers were designed on the basis of reported sequences in the National Center for Biotechnology Information PrimerBank [ $\beta$-actin: $5{ }^{\prime}$-CCTGGC ACCCAGCACAAT-3' (forward) and 5'-AGTACTCCG TGTGGATCGGC-3' (reverse); $\alpha$-SMA: 5'-CGGTGCT GTCTCTCTATGCC-3' (forward) and 5'-CGCTCAGTC AGGATCTTCA-3' (reverse); CD248: 5'-AGTGTTATT GTAGCGAGGGACA-3' (forward) and 5'-CCTCTGGG AAGCTCGGTCTA-3' (reverse)]. Results were analyzed after 45 cycles of amplification using the ABI 7500 Fast Real Time PCR System (Applied Biosystems).

\section{Statistical analysis}

Prism 5.0 software (GraphPad Software, La Jolla, CA, USA) was used for statistical analyses. Results are expressed as median (range). Owing to the nonparametric distribution of our data, the Mann-Whitney $U$ test was used as appropriate for analyses. Statistical significance was expressed by a $p$ value $<0.05$.

\section{Results}

\section{CD248 expression in skin SSc}

Our results show that CD248 is overexpressed in SSc skin, and specifically in both EC and perivascular cells, when compared with $\mathrm{HC}$ skin, as observed in Fig. 1. Consistent with these findings, in whole SSc skin biopsies, CD248 mRNA expression was significantly increased when compared with $\mathrm{HC}$ skin, as assessed by qRT-PCR. Furthermore, in LSS skin, the CD248 mRNA expression was significantly increased when compared with EOS skin (Fig. 1g).

Interestingly, we observed that CD248 expression was not limited only to the cells of blood vessels; also other cells, proximal to microvessels, showed an increased expression of this marker (Fig. 1a-d, arrowheads). To better understand our findings, we performed different staining to identify the possible lineage of these cells, and as shown in Fig. 2, these cells surrounding the vascular trees coexpressed the CD90 marker, which is highly expressed in undifferentiated MSC [34]. Of interest, these $\mathrm{CD} 90^{+} / \mathrm{CD} 248^{+}$cells were significantly increased in SSc skin when compared with $\mathrm{HC}$ skin (Fig. 2 ). Finally, the number of these $\mathrm{CD} 90^{+} / \mathrm{CD} 248^{+}$cells 


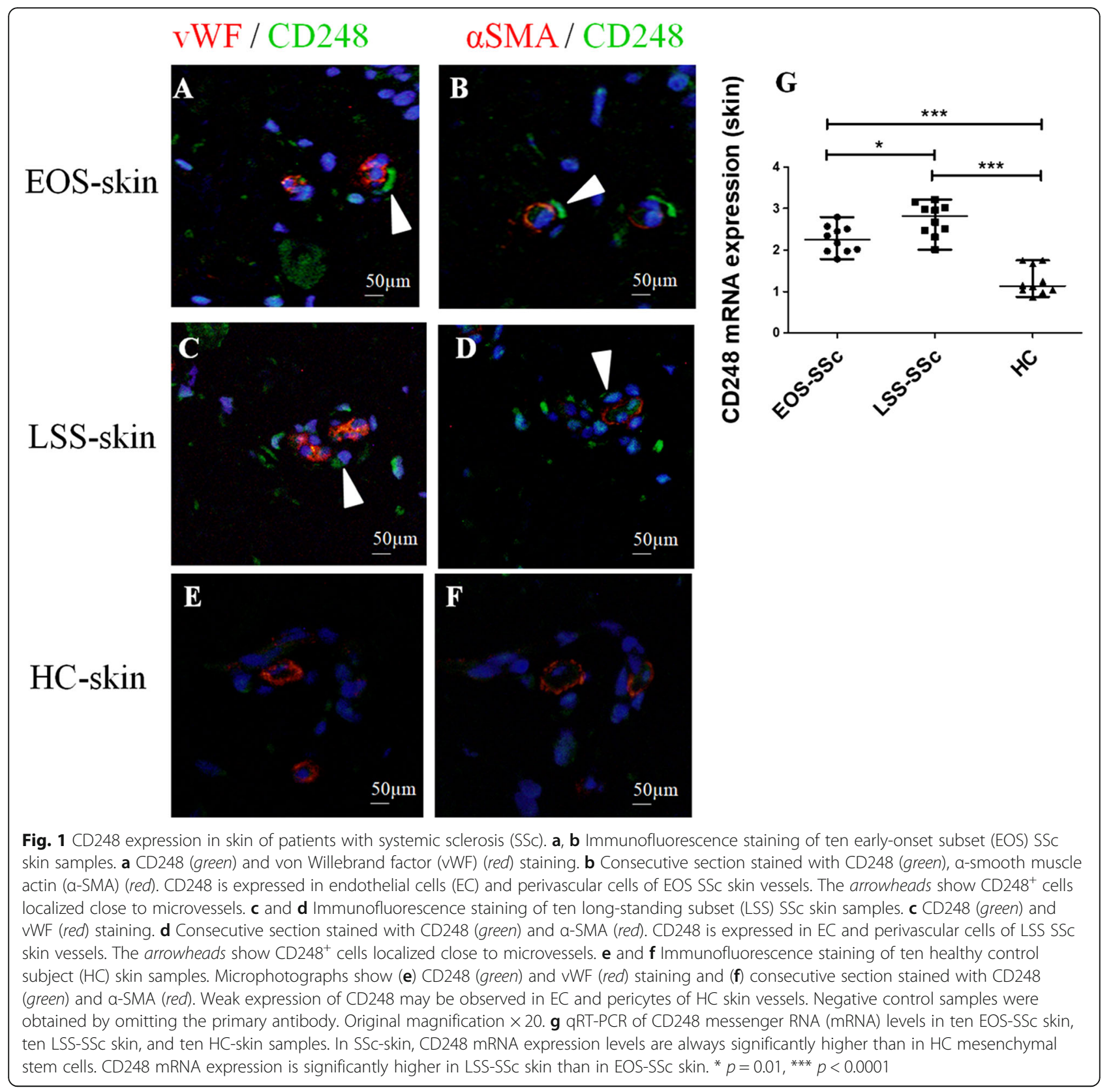

was significantly higher in LSS SSc skin (Fig. 2c and d) than in EOS SSc skin (Fig. 2a and b).

TGF- $\beta$ and PDGF-BB effects on CD248 expression in MSC

We investigated the functional role of CD248 in vitro in the perivascular differentiation toward myofibroblasts, by using MSC, a validated surrogate of perivascular cells [26]. Figure 3a shows that in SSc-MSC, CD248 mRNA expression levels were significantly higher than in HC-MSC [CD248 mRNA levels in untreated [UT] SSc-MSC 1.32 (1.25-1.50) vs UT HC-MSC 0.96 (0.73-1.17); $p<0.0001]$. Furthermore, in SSc-MSC, TGF- $\beta$ induced a significant decrease of CD248 mRNA expression levels when compared with UT SSc-MSC [CD248 mRNA levels in TGF- $\beta$ SSc-MSC $0.74(0.54-0.94)$ vs UT SSc-MSC 1.32 $(1.25-1.50) ; p<0.0001]$. In HC-MSC, the TGF- $\beta$ treatment induced a significant reduction of CD248 mRNA expression levels when compared with UT cells [CD248 mRNA levels in TGF- $\beta$ HC-MSC 0.07 (0.03-0.15) vs UT HC-MSC $0.96(0.73-1.17) ; p<0.0001]$, although in SSc-MSC, the levels of CD248 expression were always significantly higher than in HC-MSC. On the contrary, no CD248 mRNA modulation was observed by using PDGF-BB, in both SSc- and HC-MSC [CD248 mRNA levels in PDGF-BB SSc-MSC 1.69 (1.24-1.85) vs UT SSc-MSC 1.32 (1.25-1.50); $p=$ ns; CD248 mRNA levels in 


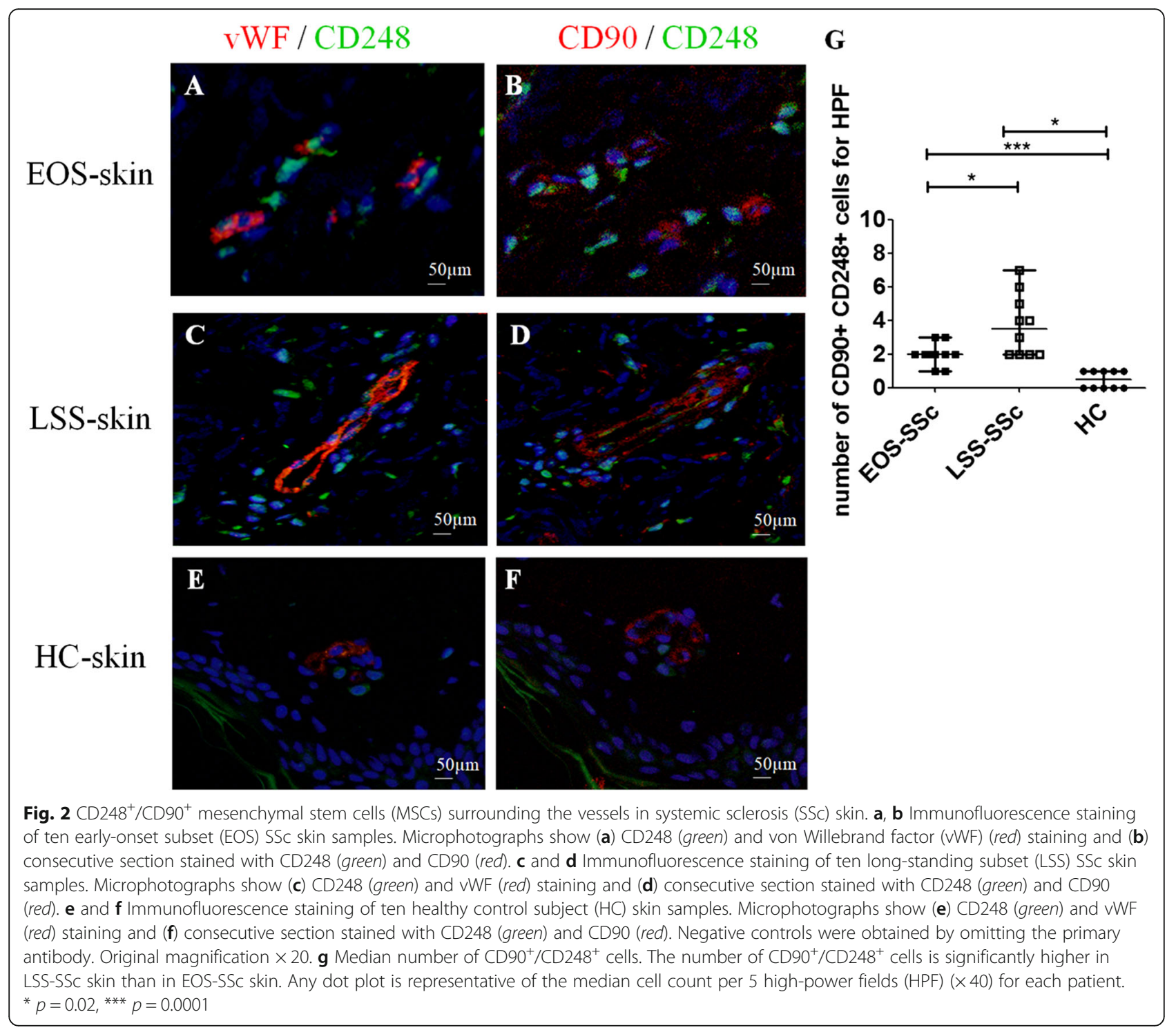

PDGF-BB HC-MSC 0.85 (0.72-1.0) vs UT HC-MSC 0.96 (0.73-1.17); $p=$ n.s.].

\section{TGF- $\beta$ induces an increase of $\alpha-S M A$ in MSC}

TGF- $\beta$ treatment induced a significant increase of $\alpha$-SMA mRNA expression in both SSc- and HC-MSC when compared with UT cells [ $\alpha$-SMA mRNA levels in TGF- $\beta$ SSc-MSC $11.90(9.36-15.87)$ vs UT SSc-MSC $7.53(6.94-7.94) ; p<0.0001 ; \alpha-S M A$ mRNA levels in TGF- $\beta$ HC-MSC $1.66(1.14-2.48)$ vs UT HC-MSC 1.05 $(0.84-1.18) ; p<0.0001]$. On the contrary, PDGF-BB treatment induced a significant decrease of $\alpha$-SMA when compared with UT cells, in both HC- and SSc-MSC [ $\alpha$-SMA mRNA levels in PDGF-BB SSc-MSC 1.84 (1.52-2.01) vs UT SSc-MSC 7.53 (6.94-7.94); $p<0.0001$; $\alpha$-SMA mRNA levels in PDGF-BB HC-MSC 0.54 (0.24$0.70)$ vs UT HC-MSC 1.05 (0.84-1.18); $p<0.0001$ ] (Fig. 3b). Western blot analysis confirmed the results of gene expression (Fig. 3d).

\section{TGF- $\beta$ and PDGF-BB effects on cell proliferation in MSC}

To assess the proliferative ability of our cells, we performed qRT-PCR for Ki-67 gene expression, a molecule considered to be associated with active proliferation. We observed that TGF- $\beta$ treatment induced a significant decrease of Ki-67 in both SSc- and HC-MSC; on the contrary, PDGF-BB induced a significant increase of Ki-67 when compared with UT cells in both SSc- and HC-MSC [Ki-67 mRNA levels in TGF- $\beta$ SSc-MSC $0.0066(0.0013-0.016)$ vs UT SSc-MSC $0.16(0.08-$ $0.23) ; \quad p<0.0001 ; \quad$ Ki-67 mRNA levels in TGF- $\beta$ HC-MSC 0.64 (0.54-0.84) vs UT HC-MSC 1.04 (0.851.26); $p<0.0001$; Ki-67 mRNA levels in PDGF-BB SSc-MSC $0.63(0.52-0.81)$ vs UT SSc-MSC $0.16(0.08-$ 

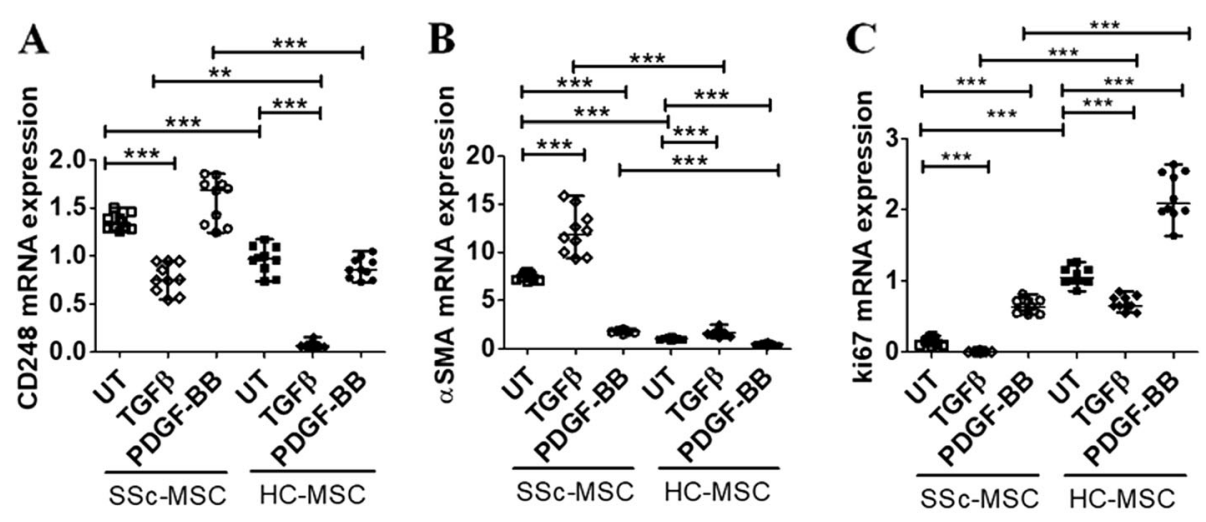

D

CD24890kd
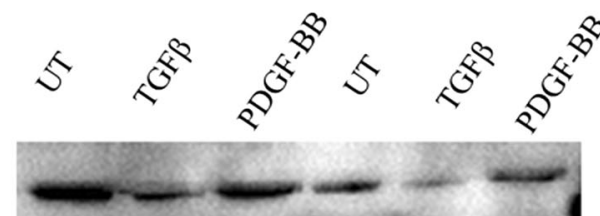

$\alpha \mathrm{SMA} 42 \mathrm{kd}$

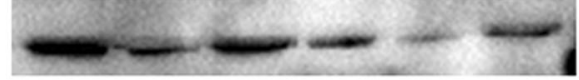

$\beta$ Actin $42 \mathrm{kd}$

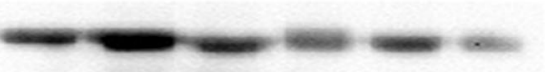

SSc-MSCs HC-MSCs

$\mathbf{E}$

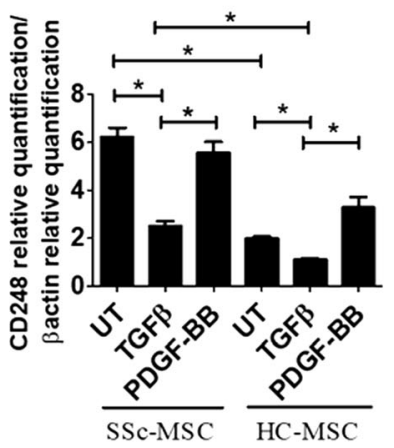

$\mathbf{F}$

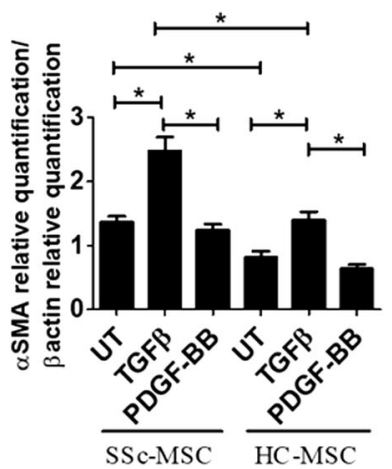

Fig. 3 Transforming growth factor (TGF)- $\beta$ and platelet-derived growth factor (PDGF)-BB effects on CD248, a-smooth muscle actin (a-SMA), and Ki-67 expression in systemic sclerosis (SSc) mesenchymal stem cells (MSCs). a qRT-PCR of CD248 messenger RNA (mRNA) levels in ten SSc-MSC (five early-onset subset [EOS] and five long-standing subset [LSS]) and ten healthy control subject (HC) MSC samples. In SSc-MSCs, CD248 mRNA expression levels are always significantly higher than in HC-MSCs. $\mathbf{b}$ qRT-PCR of a-SMA mRNA levels in ten SSC-MSCs (five EOS and five LSS) and ten HC-MSCs. In SSC-MSCs, the a-SMA mRNA levels are always significantly higher than in HC-MSCs. In both SSc- and HC-MSCS, TGF- $\beta$ treatment induces a significant increase of a-SMA mRNA expression compared with untreated (UT) cells. On the contrary, PDGF-BB treatment induces a significant decrease of a-SMA compared with UT cells in both HC- and SSc-MSCs. c qRT-PCR of Ki-67 mRNA levels in ten SSc-MSCs (five EOS and five LSS) and ten HC-MSCs. In both SSC- and HC-MSCS, TGF- $\beta$ treatment induces a significant decrease of Ki-67; on the contrary, PDGF-BB induces a significant increase of Ki-67 when compared with UT cells in both SSc- and HC-MSCs. The TGF- $\beta$ isoform used is TGF- $\beta 1$. Any single dot in the figure represents the median of triplicate experiments for each patient ${ }^{* *} p=0.0002,{ }^{* * *} p=0.0001$. d Western blot analyses performed in four SSC-MSCS (two EOS and two LSS) and four HC SSc-MSCs confirmed the results observed by GRT-PCR analyses. Pictures are representative of all experiments. e and $\mathbf{f}$ Densitometric analysis of (e) CD248 protein bands and (f) a-SMA protein bands. The values were expressed as protein relative quantification/ $\beta$-actin relative quantification. ${ }^{*} p=0.02$ 
0.23); $p<0.0001 ;$ Ki-67 mRNA levels in PDGF-BB HC-MSC 2.08 (1.63-2.63) vs UT HC-MSC 1.04 (0.85$1.26) ; p<0.0001$ ] (Fig. 3c).

\section{CD248 silencing interferes with PDGF-BB and TGF- $\beta$ signaling in SSc-MSC}

To address the role of CD248 in this cytokine network, we inactivated CD248 gene product in SSc-MSC by transfecting these cells with CD248-siRNA or scr-siRNA. CD248-siRNA efficiently knocked down CD248 molecules in SSc-MSC (> 71\%), and, after silencing, TGF- $\beta$ was unable to modulate the CD248 expression (Fig. 4a). Figure 4b shows that in CD248 silenced MSC, TGF- $\beta$ stimulation did not induce $\alpha$-SMA mRNA upregulation. Furthermore, in the same cells, PDGF-BB was unable to induce an increased expression of Ki-67 gene levels when compared with scr-siRNA-treated MSC (Fig. 4c).
Western blot analysis confirmed the results of gene expression (Fig. 4d).

\section{Discussion}

This report is the first, to the best of our knowledge, indicating that CD248, first identified as a tumor vascular endothelial antigen [35] and considered a key molecule of myofibroblast generation, is deeply involved in TGF- $\beta$ and PDGF-BB signaling transduction during the fibrosis associated with SSc and that its inhibition strongly interferes with the profibrotic pathways of these two cytokines. Recently, CD248 has been considered as a marker of stromal fibroblasts, pericyte subsets, and human MSC $[36,37]$, and in the experimental model of fibrosis, after UUO, a significant upregulation of CD248 was observed [3]. On the contrary, CD248 $8^{-/-}$mice were protected from renal fibrosis and capillary rarefaction, probably

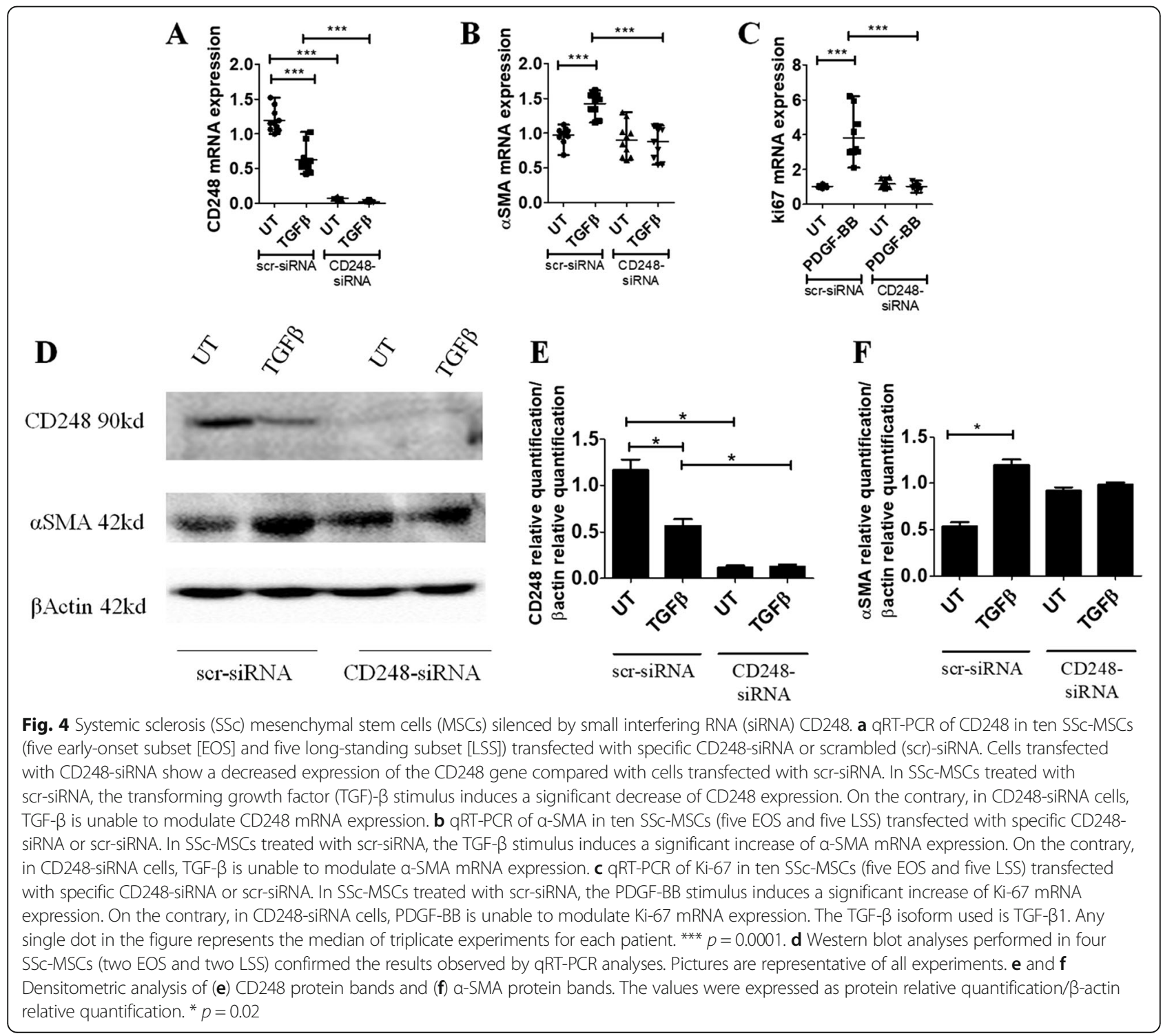


inhibiting pericyte differentiation toward $\alpha-\mathrm{SMA}^{+}$interstitial myofibroblasts and preventing vascular instability and collagen production [3]. Furthermore, it has been reported that CD248 expressed on pericytes can promote EC apoptosis, probably impairing the cross-talk between EC integrins and vascular endothelial growth factor (VEGF) receptor 2, leading to the attenuation of VEGF signaling [38]. On these bases, CD248 may be considered a key target in those pathologic processes in which vascular damage and fibrosis are strongly joined in SSc.

In our present study, we chose to include in the patient cohort only patients affected by the $\mathrm{Scl} 70^{+}$diffuse form of the disease, because this subset rapidly progresses from vascular damage to fibrosis and may be considered a good "human model" to evaluate the link between vascular damage and fibrosis. In fact, it is well known that anti-Scl70 antibody is one of the typical autoimmune markers in SSc, occurring in $60.8 \%$ of cases of diffuse SSc and $23.4 \%$ of cases of limited SSc [39]. The presence of anti-Scl70 antibody is associated with severity of the disease, decreased survival [40], and evidence of pulmonary fibrosis [41]. We observed that CD248 was constitutively overexpressed on SSc cells derived from mesenchymal lineage. In SSc skin, we observed that CD248 was expressed on stromal fibroblasts and perivascular cells located in close proximity to the vessel, when compared with healthy skin, and the number of $\mathrm{CD} 248^{+}$cells significantly increased over time. Furthermore, in LSS-SSc biopsy, the CD248 mRNA expression of whole biopsy was significantly increased when compared with EOS-SSc. Of note, IF showed that the $\mathrm{CD} 248^{+}$cells coexpressed CD90, a molecule highly expressed in all the undifferentiated MSC [42, 43]. Currently, although we do not have a single cell marker capable of defining MSC, available literature suggests that CD90, which is highly expressed in all MSC, regardless of the source, may be considered a good marker to identify undifferentiated MSC [34]. The increased CD248 expression in perivascular cells of patients with SSc highly coexpressing the stem marker CD90 may suggest that in these MSC, both the profibrotic machinery and cells' differentiation toward myofibroblasts may be activated.

Furthermore, our results showed that increased CD248 expression may be observed also in EC of SSc skin biopsies. It has been reported that CD248 may be expressed by endothelial progenitor cells [44] and tumor EC, together with pericytes and tumor-associated fibroblasts, during active cancer angiogenesis $[38,45]$. It has been proposed that CD248 expressed by EC may interact with ECM proteins as well as tumor stromal cells to promote vascular invasion and migration [46]; in fact, CD248 expression was induced in EC when cultured in Matrigel, suggesting that endosialin could be induced in
EC exposed to a complex extracellular environment [46]. In our setting, we hypothesize that SSc-EC may express CD248 as a compensatory mechanism to support angiogenesis in the context of a disease characterized by progressive desertification of vascular tree.

We investigated the functional role of CD248 in vitro in the perivascular differentiation toward myofibroblasts by using MSC, a validated surrogate of perivascular cells $[26,47]$. Although the possible role of the CD248 molecule in SSc pathogenesis is largely unknown, it has been reported that this molecule is involved in the fibroproliferative process by modulating the PDGF-BB pathway [21] and collaborating with the TGF- $\beta$ pathway to induce $\alpha$-SMA expression [48]. In HC cells, TGF- $\beta$ induced significantly decreased of CD248 when compared with UT cells. On the contrary, SSc-MSC displayed significantly higher CD248 expression than $\mathrm{HC}$ cells in both TGF- $\beta$-stimulated and unstimulated cultures. Recently, it has been shown that TGF- $\beta$ strongly suppresses CD248 expression in healthy murine fibroblast cell lines; on the contrary, during cancer, where significantly higher CD248 levels are reported, mirroring what we observed in our cells, TGF- $\beta$ failed to downregulate CD248 expression [49]. Although TGF- $\beta$ is not a promoter of CD248 expression, CD248 may collaborate with TGF- $\beta$ to induce $\alpha$-SMA, possibly via downregulation of Notch3 $[9,12]$ and upregulation of interleukin 6 (IL6), C-C motif chemokine ligand 2 (CCL2), TGF- $\beta 1$, and TGF- $\beta$ R1 [48]. In fact, it has been reported that Notch 3 may prevent the TGF- $\beta 1$ induction of $\alpha$-SMA, working as a molecular brake on smooth muscle gene transcription [50]. Furthermore, IL6, CCL2, TGF- $\beta 1$, and TGF- $\beta$ R1, activated by CD248, may strongly stimulate $\alpha$-SMA [51]. Thus, we may hypothesize that CD248 overexpression in SSc-MSC may play its profibrotic role, exacerbating the TGF- $\beta$ effects [52], by removing the Notch 3 control and promoting $\alpha$-SMA expression by its own downstream mediators. In fact, after silencing CD248, cells were unable to induce $\alpha$-SMA expression after TGF- $\beta$ stimulus, thus confirming the key role of CD248 in increasing the TGF- $\beta$ effects in SSc-MSC.

To date, conflicting results have been reported in available literature concerning the expression of different smooth muscle genes during fibroblast proliferation and activation. Transcript levels of $\mathrm{Sm} 22$ are elevated in fibroblasts derived from mice lacking the cytoplasmic domain of CD248 [12], and CD248 knockdown did not affect the in vitro expression of $\alpha$-SMA in normal human lung fibroblast [31]. On the contrary, in in vitro cultured human pericytes, the ability of TGF- $\beta$ to induce $\alpha$-SMA expression was lost in the CD248-specific siRNA-transfected primary human brain vascular pericytes, suggesting that $\alpha$-SMA induction is CD248-dependent [53]. Furthermore, in an experimental model of liver fibrosis, the total liver 
mRNA of collagen and $\alpha$-SMA was reduced in CD248-deficient mice compared with wild-type mice [19], and in a model of renal fibrosis, no increase of $\alpha$-SMA molecule was observed in CD248-deficient mice [8]. These discrepancies may be partially explained by the different experimental models, the differences in cell manipulation, the intensity and quality of stimuli, and the different levels of efficacy in CD248 silencing.

To assess the contribution of CD248 in modulating the proliferative ability of SSc-MSC, we evaluated the expression of Ki-67 gene expression, which strongly correlates with cellular proliferation [19]. PDGF-BB induced a significant increase of $\mathrm{Ki}-67$ levels when compared with UT cells in both HC- and SSc-MSC.

The role of CD248 in PDGF-BB signaling has been studied in human pericytes and hepatic stellate cells (HSC), commonly considered the precursors of septal myofibroblasts in liver fibrosis. PDGF-BB currently is considered one of the most potent HSC mitogens known, and it plays a key regulatory role in HSC proliferation during hepatic fibrogenesis [19]. It has been proposed that CD248 regulates the PDGF-BB pathway, thus controlling cell proliferation [54].

After CD248 silencing, we observed a strong inhibition of PDGF-BB-mediated cell proliferation, suggesting that this process is under CD248 control, thus decreasing the myofibroblast accumulation and confirming previous reports [23] in which primary renal fibroblasts isolated from CD248-knockout mice displays both decreased cell proliferation and reduced collagen secretion when compared with wild-type mice. Currently, it is still unclear how CD248 may modulate this proliferative signal: via the matrix-binding properties of CD248 and/or by the well-known ability of this molecule to potentiate PDGF-BB signaling. Recent studies in hepatic fibrosis, however, have provided evidence that HSC CD248 ${ }^{-/-}$ display normal levels of PDGF receptors, suggesting that the antiproliferative effect of CD248 ${ }^{-/-}$HSCs is not mediated through the modulation of PDGF receptor expression [19].

\section{Conclusions}

Our study shows that SSc perivascular cells overexpress CD248, which is involved in SSc pericyte transition toward myofibroblasts, and CD248 silencing may prevent pericyte-to-myofibroblast transition, proliferation, vascular instability, and tissue fibrosis. Taken together, our data suggest that targeting CD248 expression may be considered a potential target in order to block tissue fibrosis and vascular desertification during SSc.

\section{Abbreviations}

CCL2: C-C motif chemokine ligand 2; CDNA: Complementary DNA; ECM: Extracellular matrix; EC: Endothelial cell(s); EOS: Early-onset subset; HC: Healthy control subject(s); HSC: Hepatic stellate cell(s);
IF: Immunofluorescence; IL6: Interleukin 6; LSS: Long-standing subset; mRNA: Messenger RNA; MSC: Mesenchymal stem cell(s); PDGF-BB: Platelet-derived growth factor BB; RP: Raynaud's phenomenon; scrsiRNA: Nontargeting scrambled small interfering RNA; siRNA: Small interfering RNA; a-SMA: a-Smooth muscle actin; SSc: Systemic sclerosis; TGF$\beta$ : Transforming growth factor- $\beta$; UUO: Unilateral ureteral obstruction; VEGF: Vascular endothelial growth factor; vWF: Von Willebrand factor

\section{Acknowledgements}

The authors thank Federica Sensini and Anna Rita Lizzi for their technical assistance.

\section{Availability of data and materials}

Relevant files of this work will be shared on reasonable request.

\section{Authors' contributions}

PDB was responsible for study conception and design, data interpretation, literature search, figure creation, manuscript writing, and paper revision and approval. VL was responsible for data collection, data interpretation, literature search, and paper revision and approval. PR was responsible for data collection, data interpretation, literature search, and paper revision and approval. OB was responsible for data collection, data interpretation, literature search, and paper revision and approval. FCa was responsible for data collection, data interpretation, literature search, and paper revision and approval. NP was responsible for data collection, data interpretation, literature search, and paper revision and approval. SDB was responsible for data collection, data interpretation, literature search, and paper revision and approval. $\mathrm{FCi}$ was responsible for data collection, data interpretation, literature search, and paper revision and approval. GG was responsible for data collection, data interpretation, literature search, and paper revision and approval. GT was responsible for data collection, data interpretation, literature search, and paper revision and approval. PC was responsible for study conception and design, data interpretation, manuscript writing, and paper revision and approval. RG was responsible for study conception and design, data interpretation, manuscript writing, and paper revision and approval. All authors gave final approval for submitting the manuscript for review and agree to be accountable for all aspects of the work.

\section{Ethics approval and consent to participate}

The experiments reported in this article comply with the current ethical standard laws of Italy. All patients gave fully informed written consent approved by the institutional ethics committee.

Consent for publication

Not applicable.

\section{Competing interests}

The authors declare that they have no competing interests.

\section{Publisher's Note}

Springer Nature remains neutral with regard to jurisdictional claims in published maps and institutional affiliations.

\section{Author details}

${ }^{1}$ Department of Biotechnological and Applied Clinical Sciences, Rheumatology Unit, School of Medicine, University of L'Aquila, Delta 6 Building, Via dell'Ospedale, 67100 L'Aquila, Italy. ${ }^{2}$ Department of Internal Medicine, Division of Rheumatology, University of Palermo, Piazza delle Cliniche 2, 90127 Palermo, Italy.

Received: 6 June 2018 Accepted: 10 September 2018 Published online: 03 October 2018

\section{References}

1. Lax S, Hardie D, Wilson A, Douglas M, Anderson G, Huso D, et al. The pericyte and stromal marker CD248 (endosialin) is required for efficient lymph node expansion. Eur J Immunol. 2010;40:1884-9.

2. Bagley RG, Honma N, Weber W, Boutin P, Rouleau C, Shankara S, et al. Endosialin/TEM1/CD248 is a pericyte marker of embryonic and tumor neovascularisation. Microvasc Res. 2008;76:180-8. 
3. Smith SW, Eardley KS, Croft A, Nwosu J, Howie AJ, Cockwell P, et al. CD248 stromal cells are associated with progressive chronic kidney disease. Kidney Int. 2011;80:199-207.

4. Maia M, de Vriese A, Janssens T, Moons M, van Landuyt K, Tavernier J, et al. CD248 and its cytoplasmic domain: a therapeutic target for arthritis. Arthritis Rheum. 2010;62:3595-606.

5. Rettig WJ, Garin-Chesa P, Healey JH, Su SL, Jaffe EA, Old LJ. Identification of endosialin, a cell surface glycoprotein of vascular endothelial cells in human cancer. Proc Natl Acad Sci U S A. 1992;89:10832-6.

6. Rouleau C, Curiel M, Weber W, Smale R, Kurtzberg L, Mascarello J, et al. Endosialin protein expression and therapeutic target potential in human solid tumors: sarcoma versus carcinoma. Clin Cancer Res. 2008;14:7223-36.

7. Brady J, Neal J, Sadakar N, Gasque P. Human endosialin (tumor endothelia marker 1 ) is abundantly expressed in highly malignant and invasive brain tumors. J Neuropathol Exp Neurol. 2004:63:2374-83.

8. Smith SW, Croft AP, Morris HL, Naylor AJ, Huso DL, Isacke CM, Savage CO, Buckley CD. Genetic deletion of the stromal cell marker CD248 (endosialin) protects against the development of renal fibrosis. Nephron. 2015;131:265-77.

9. Chang-Panesso M, Humphreys BD. CD248/endosialin: a novel pericyte target in renal fibrosis. Nephron. 2015;131:262-4.

10. Maia M, DeVriese A, Janssens T, Moons M, Lories RJ, Tavernier J, et al. CD248 facilitates tumor growth via its cytoplasmic domain. BMC Cancer. 2011:11:162.

11. Teicher BA. Newer vascular targets: endosialin (review). Int J Oncol. 2007;30: 305-12.

12. Valdez Y, Maia M, Conway EM. CD248: reviewing its role in health and disease. Curr Drug Targets. 2012;13:432-9.

13. Diaz LA, Coughlin CM, Weil SC, Fishel J, Gounder MM, Lawrence S, et al. A first-in-human phase I study of MORAb-004, a monoclonal antibody to endosialin in patients with advanced solid tumors. Clin Cancer Res. 2015;21: 1281-8.

14. Denton CP, Black CM, Abraham DJ. Mechanisms and consequences of fibrosis in systemic sclerosis. Nat Clin Pract Rheumatol. 2006;2:134-44.

15. Gabrielli A, Avvedimento EV, Krieg T. Scleroderma. N Engl J Med. 2009;360: 1989-2003.

16. Cipriani P, Di Benedetto P, Ruscitti P, Capece D, Zazzeroni F, Liakouli V, et al. The endothelial-mesenchymal transition in SSc is induced by the synergistic effect of ET-1 and TGF- $\beta$ and may be blocked by macitentan, a new dual ET-1 receptor antagonist. J Rheumatol. 2015;42:1808-16.

17. Cipriani P, Di Benedetto P, Ruscitti P, Campese AF, Liakouli V, Carubbi F, et al. Impaired endothelium-mesenchymal stem cells cross-talk in systemic sclerosis: a link between vascular and fibrotic features. Arthritis Res Ther. 2014;16:442.

18. Jimenez SA. Role of endothelial to mesenchymal transition in the pathogenesis of the vascular alterations in systemic sclerosis. ISRN Rheumatol. 2013;23:835948.

19. Wilhelm A, Aldridge V, Haldar D, Naylor AJ, Weston CJ, Hedegaard D, et al. CD248/endosialin critically regulates hepatic stellate cell proliferation during chronic liver injury via a PDGF-regulated mechanism. Gut. 2016;65:1175-85.

20. Cipriani P, Di Benedetto P, Dietrich H, Ruscitti P, Liakouli V, Carubbi F, Pantano I, Berardicurti O, Sgonc R, Giacomelli R. Searching for a good model for systemic sclerosis: the molecular profile and vascular changes occurring in UCD-200 chickens strongly resemble the early phase of human systemic sclerosis. Arch Med Sci. 2016;12:828-43.

21. Jiménez SA, Castro SV, Piera-Velázquez S. Role of growth factors in the pathogenesis of tissue fibrosis in systemic sclerosis. Curr Rheumatol Rev. 2010;6:283-94

22. Sacchetti C, Bai Y, Stanford SM, Di Benedetto P, Cipriani P, Santelli E, et al. PTP4A1 promotes TGF $\beta$ signaling and fibrosis in systemic sclerosis. Nat Commun. 2017:8(1):1060

23. Cipriani P, Di Benedetto P, Liakouli V, Del Papa B, Di Padova M, Di lanni M, Marrelli A, Alesse E, Giacomelli R. Mesenchymal stem cells (MSCs) from scleroderma patients (SSc) preserve their immunomodulatory properties although senescent and normally induce T regulatory cells (Tregs) with a functional phenotype: implications for cellular-based therapy. Clin Exp Immunol. 2013;173:195-206.

24. Cipriani P, Marrelli A, Liakouli V, Di Benedetto P, Giacomelli R. Cellular players in angiogenesis during the course of systemic sclerosis. Autoimmun Rev. 2011;10:641-6.

25. Cipriani $P$, Di Benedetto $P$, Ruscitti $P$, Liakouli $V$, Berardicurti $O$, Carubbi $F$, et al. Perivascular cells in diffuse cutaneous systemic sclerosis overexpress activated ADAM12 and are involved in myofibroblast transdifferentiation and development of fibrosis. J Rheumatol. 2016:43:1340-9.

26. Cipriani P, Marrelli A, Di Benedetto P, Liakouli V, Carubbi F, Ruscitti P, et al. Scleroderma mesenchymal stem cells display a different phenotype from healthy controls; implications for regenerative medicine. Angiogenesis. 2013;16:595-607.

27. LeRoy EC, Black C, Fleischmajer R, Jablonska S, Krieg T, Medsger TA, et al. Scleroderma (systemic sclerosis): classification, subsets and pathogenesis. J Rheumatol. 1988;15:202-5.

28. van den Hoogen F, Khanna D, Fransen J, Johnson SR, Baron M, Tyndall A, et al. 2013 Classification criteria for systemic sclerosis: an American College of Rheumatology/European League Against Rheumatism collaborative initiative. Ann Rheum Dis. 2013;72:1747-55.

29. Kahaleh MB, Sultany GL, Smith EA, Huffstutter JE, Loadholt CB, Le Roy EC. A modified scleroderma skin scoring method. Clin Exp Rheumatol. 1986:4:367-9.

30. Koenig M, Joyal F, Fritzler MJ. Autoantibodies and microvascular damage are independent predictive factors for the progression of Raynaud's phenomenon to systemic sclerosis: a twenty-year prospective study of 586 patients, with validation of proposed criteria for early systemic sclerosis. Arthritis Rheum. 2008:58:3902-12

31. Bartis D, Crowley LE, D'Souza VK, Borthwick L, Fisher AJ, Croft AP, et al. Role of CD248 as a potential severity marker in idiopathic pulmonary fibrosis. BMC Pulm Med. 2016;16:51.

32. Huang HP, Hong $C L$, Kao CY, Lin SW, Lin SR, Wu HL et al. Gene targeting and expression analysis of mouse Tem1/endosialin using a lacZ reporter. Gene Expr Patterns. 2011;11:316-26.

33. Christian S, Ahorn H, Koehler A, Eisenhaber F, Rodi HP, Garin-Chesa P, et al. Molecular cloning and characterization of endosialin, a C-type lectin-like cell surface receptor of tumor endothelium. J Biol Chem. 2001;276:7408-14.

34. Moraes DA, Sibov TT, Pavon LF, Alvim PQ, Bonadio RS, Da Silva JR, et al. A reduction in CD90 (THY-1) expression results in increased differentiation of mesenchymal stromal cells. Stem Cell Res Ther. 2016;7:97.

35. Christian S, Winkler R, Helfrich I, Boos AM, Besemfelder E, Schadendorf D, Augustin HG. Endosialin (Tem1) Is a Marker of Tumor-Associated Myofibroblasts and Tumor Vessel-Associated Mural Cells. Am J Pathol. 2008; 172(2):486-94.

36. MacFadyen JR, Haworth O, Roberston D, Hardie D, Webster MT, Morris HR et al. Endosialin (TEM1, CD248) is a marker of stromal fibroblasts and is not selectively expressed on tumour endothelium. FEBS Lett. 2005;579:2569-75.

37. Bagley RG, Weber W, Rouleau C, Yao M, Honma N, Kataoka S, et al. Human mesenchymal stem cells from bone marrow express tumor endothelial and stromal markers. Int J Oncol. 2009;34:619-27.

38. Simonavicius N, Robertson D, Bax DA, Jones C, Huijbers IJ, Isacke CM. Endosialin (CD248) is a marker of tumor-associated pericytes in high-grade glioma. Mod Pathol. 2008;21:308-15.

39. Walker UA, Tyndall A, Czirják L, Denton C, Farge-Bancel D, Kowal-Bielecka O, et al. Clinical risk assessment of organ manifestations in systemic sclerosis: a report from the EULAR Scleroderma Trials and Research group database. Ann Rheum Dis. 2007:66:754-63.

40. Jacobsen S, Ullman S, Shen GQ, Wiik A, Halberg P. Influence of clinical features, serum antinuclear antibodies, and lung function on survival of patients with systemic sclerosis. J Rheumatol. 2001;28:2454-9.

41. Diot E, Giraudeau B, Diot P, Degenne D, Ritz L, Guilmot JL, et al. Is antitopoisomerase I a serum marker of pulmonary involvement in systemic sclerosis? Chest. 1999;116:715-20.

42. Dominici M, Le Blanc K, Mueller I, Marini FC, Krause DS, Deans RJ, et al. Minimal criteria for defining multipotent mesenchymal stromal cells: the International Society for Cellular Therapy position statement. Cytotherapy. 2006;8:315-7.

43. Horwitz EM, Le Blanc K, Dominici M, Mueller I, Slaper-Cortenbach I, Marini FC, et al. Clarification of the nomenclature for MSC: the International Society for Cellular Therapy position statement. Cytotherapy. 2005;7:393-5.

44. Bagley RG, Rouleau C, St Martin T, Boutin P, Weber W, Ruzek M, et al. Human endothelial precursor cells express tumor endothelial marker 1/ endosialin/CD248. Mol Cancer Ther. 2008:7:2536-46.

45. Wesseling P, Schlingemann RO, Rietveld FJ, Link M, Burger PC, Ruiter DJ. Early and extensive contribution of pericytes/vascular smooth muscle cells to microvascular proliferation in glioblastoma multiforme: an immuno-light and immuno-electron microscopic study. J Neuropathol Exp Neurol. 1995:54:304-10.

46. Carson-Walter EB, Winans BN, Whiteman MC, Liu Y, Jarvela S, Haapasalo H, et al. Characterization of TEM1/endosialin in human and murine brain tumors. BMC Cancer. 2009;9:417. 
47. Crisan M, Yap S, Casteilla L, Chen CW, Corselli M, Park TS, et al. A perivascular origin for mesenchymal stem cells in multiple human organs. Cell Stem Cell. 2008;3:301-13.

48. Kontsekova S, Polcicova K, Takacova M, Pastorekova S. Endosialin: molecular and functional links to tumor angiogenesis. Neoplasma. 2016;63:183-92.

49. Suresh Babu S, Valdez Y, Xu A, O'Byrne AM, Calvo F, Lei V, et al. TGFßmediated suppression of CD248 in non-cancer cells via canonical Smaddependent signaling pathways is uncoupled in cancer cells. BMC Cancer. 2014;14:113.

50. Kennard S, Liu H, Lilly B. Transforming growth factor- $\beta$ (TGF-1) downregulates Notch3 in fibroblasts to promote smooth muscle gene expression. J Biol Chem. 2008;283:1324-33.

51. Murray LA, Argentieri RL, Farrell FX, Bracht M, Sheng H, Whitaker B, et al. Hyper-responsiveness of IPF/UIP fibroblasts: interplay between TGF $\beta 1$, IL-13 and CCL2. Int J Biochem Cell Biol. 2008:40:2174-82.

52. Cipriani P, Di Benedetto P, Ruscitti P, Verzella D, Fischietti M, Zazzeroni F, et al. Macitentan inhibits the transforming growth factor- $\beta$ profibrotic action, blocking the signaling mediated by the ETR/TRRI complex in systemic sclerosis dermal fibroblasts. Arthritis Res Ther. 2015;17:247.

53. Rybinski K, Imtiyaz HZ, Mittica B, Drozdowski B, Fulmer J, Furuuchi K Fernando S, Henry M, Chao Q, Kline B, Albone E, Wustner J, Lin J, Nicolaides NC, Grasso L, Zhou Y. Targeting endosialin/CD248 through antibodymediated internalization results in impaired pericyte maturation and dysfunctional tumor microvasculature. Oncotarget. 2015;22:25429-40.

54. Tomkowicz B, Rybinski K, Sebeck D, Sass P, Nicolaides NC, Grasso L, et al. Endosialin/TEM-1/CD248 regulates pericyte proliferation through PDGF receptor signaling. Cancer Biol Ther. 2010;9:908-15.

Ready to submit your research? Choose BMC and benefit from:

- fast, convenient online submission

- thorough peer review by experienced researchers in your field

- rapid publication on acceptance

- support for research data, including large and complex data types

- gold Open Access which fosters wider collaboration and increased citations

- maximum visibility for your research: over $100 \mathrm{M}$ website views per year

At BMC, research is always in progress.

Learn more biomedcentral.com/submissions 